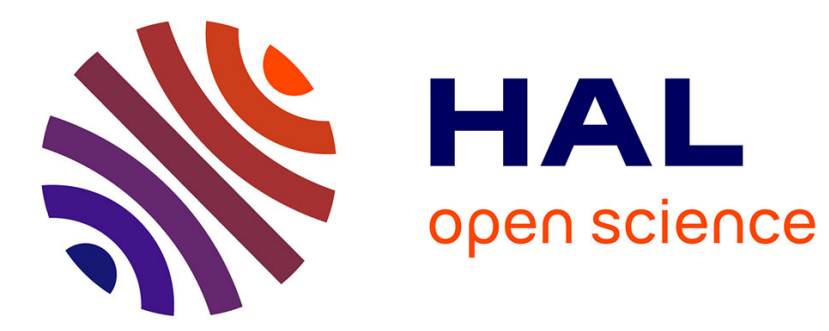

\title{
Mapping grassland plant communities using a fuzzy approach to address floristic and spectral uncertainty
}

Sébastien Rapinel, Nicolas Rossignol, Laurence Hubert-Moy, Jan-Bernard Bouzillé, Anne Bonis

\section{- To cite this version:}

Sébastien Rapinel, Nicolas Rossignol, Laurence Hubert-Moy, Jan-Bernard Bouzillé, Anne Bonis. Mapping grassland plant communities using a fuzzy approach to address floristic and spectral uncertainty. Applied Vegetation Science, 2018, 21 (4), pp.678-693. 10.1111/avsc.12396 . hal-01937631

\section{HAL Id: hal-01937631}

\section{https://hal-univ-rennes1.archives-ouvertes.fr/hal-01937631}

Submitted on 17 Dec 2020

HAL is a multi-disciplinary open access archive for the deposit and dissemination of scientific research documents, whether they are published or not. The documents may come from teaching and research institutions in France or abroad, or from public or private research centers.
L'archive ouverte pluridisciplinaire HAL, est destinée au dépôt et à la diffusion de documents scientifiques de niveau recherche, publiés ou non, émanant des établissements d'enseignement et de recherche français ou étrangers, des laboratoires publics ou privés. 
2 Title: Mapping grassland plant communities using a fuzzy approach to address floristic and

3 spectral uncertainty

\section{Author names and addresses:}

5 Rapinel, S. (corresponding author, sebastien.rapinel@univ-rennes2.fr) ${ }^{1,2}$

6 Rossignol, N. (nicolas.rossignol@univ-rennes1.fr) ${ }^{1}$

$7 \quad$ Hubert-Moy, L. (laurence.moy@univ-rennes2.fr) ${ }^{2}$

8 Bouzillé, J.B. (jan-bernard.bouzille@univ-rennes1.fr) ${ }^{1}$

9 Bonis, A. (anne.bonis@univ-rennes1.fr) ${ }^{1(a)}$

${ }^{1}$ CNRS UMR 6553 ECOBIO, Université Rennes 1, Avenue Général Leclerc, 35000 Rennes,

11 France

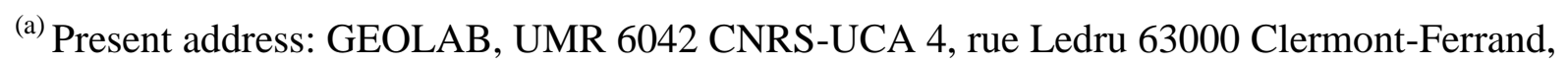
France, anne.bonis@uca.fr

${ }^{2}$ CNRS UMR 6554 LETG, Université Rennes 2, Place du Recteur Henri Le Moal, 35000

Rennes, France

Printed journal page estimate: 10680 words (13.0 pages), tables 1.0 pages, figures 2.0 pages, total 16.0 pages. 
Abstract:

Aims: The mapping and monitoring of natural vegetation is a challenging but important objective for environmental management. Although remote sensing has been used to map plant communities for several years, the maps produced are not sufficiently accurate to meet management requirements. This can be explained by the cumulative effects of floristic and spectral uncertainty. The objective of this study was to accurately map grassland plant communities using a comprehensive fuzzy approach in order to address floristic and spectral uncertainty.

Location: Sub-brackish wet grasslands, Marais Poitevin, France.

Methods: We first created a compromise typology - floristically and spectrally consistent - to perform fuzzy noise clustering on a joint PCA matrix derived from vegetation relevés and remote sensing data. This typology had two levels, which corresponded to spectral signatures and plant communities, respectively. Second, we mapped grassland plant communities to predict the fuzzy model from the remote sensing data. We applied this approach using 1- a very high spatial resolution multispectral satellite image and a LiDAR-derived Digital Terrain Model acquired on a $73 \mathrm{~km}^{2}$ wet grassland site and 2- more than 200 relevés collected in the field.

Results: The results show that 1 - the compromise typology yields significantly higher mapping accuracy than classic phytosociological typology (62\% and 26\%, respectively); 2compared to a crisp approach, the fuzzy approach improves mapping accuracy by 17 percentage points and 3- a single plant community can be defined by several (1-4) distinct spectral signatures.

Conclusions: The comprehensive fuzzy procedure successfully mapped herbaceous plant communities at the ecosystem scale using inexpensive remote sensing data. Floristic and 
44 spectral uncertainty was considered in a fuzzy approach, resulting in the mapping of 9

45 herbaceous plant communities with acceptable accuracy. As the natural habitats were characterized at the plant community level, correspondence with functional properties of the

47 species or with ecosystem services can be easily inferred. These encouraging results open up 48 new ways to meet the requirements for monitoring the conservation status of natural habitats 49 in the EU Habitats Directive.

50 Key-words: LiDAR, noise clustering, phytosociology, Pléiades, remote sensing, vegetation 51 typology, wetlands.

52

53 Nomenclature: Gargominy et al. (2012) for vascular plants; Bioret et al. (2013) for plant 54 communities

55 56

Running head: Mapping plant communities using a fuzzy approach 57 


\section{Introduction}

Faced with intensive agriculture, urbanization and climate change, the mapping and monitoring of natural habitats is still a major challenge for conservation management. This has very important consequences for herbaceous habitats (lawns, meadows) with strong conservation stakes (Council Directive 92/43/EEC) that cover more than 30\% of European areas (Peeters 2009). Within this context, a spatio-temporal monitoring of natural habitats over hundreds of $\mathrm{km}^{2}$ is needed to meet reporting requirements for the conservation status of European NATURA 2000 sites. To meet this requirement, natural habitats should be identified at the plant community level in order to assess the heritage quality (Berg et al. 2014), ecosystem services (Lavorel et al. 2011) and impacts of agricultural practices or water level management on vegetal biodiversity (Dumont et al. 2012; Stratford et al. 2015).

It seems as though remote sensing data are an attractive resource for monitoring the spatiotemporal dynamics of natural grassland habitats (Vanden Borre et al. 2011). Numerous studies have pointed out the contribution of satellite imagery for measuring species richness (Rocchini et al. 2016) or predicting functional traits in grasslands (Lausch et al. 2016). However, it remains a challenging task to accurately map grassland plant communities using remote sensing data (Corbane et al. 2015; Lang et al. 2015), due to floristic uncertainty and spectral uncertainty. The floristic uncertainty is the inevitable probability of misclassifying vegetation relevés (De Cáceres et al. 2010), which is especially high when handling plant communities with similar species compositions. Spectral uncertainty is related to the misclassification of remote sensing data explained by the spectral similarities between plant communities (Rocchini et al. 2013). The spectral response(s) of a plant community partially reflect(s) its floristic composition (Rocchini \& Cade 2008). Local contrasts in environmental conditions, such as soil wetness and nutrient contents as well as individual plant interactions, occur on very small scales, i.e. several square meters (Marion et al. 2010; Dumont et al. 
2012). Consequently, the resulting fine-grained mosaic patterns of the vegetation show variable spectral response(s) (Feilhauer et al. 2013; Kumar \& Sinha 2014) and this spectral variance reduces the distinctiveness of the various plant communities (Ali et al. 2016).

Conversely, grassland plant communities have a similar physiognomy, as they are dominated by herbaceous graminoid species with a height range between $20 \mathrm{~cm}$ and $1 \mathrm{~m}$ in general. As a result, the physiognomic similarity of grassland plant communities smooths out the spectral variability between them (Rocchini et al. 2013).

To address these issues, many approaches have been developed to accurately map natural habitats, such as (1) simplifying the vegetation typology at the expense of ecological consistency, (2) using remote sensing satellite image time series, (3) considering vegetation as a continuum rather than as plant communities and (4) applying fuzzy approaches:

1. Vegetation typologies have been created to fit spectral data variance, using multivariate analyses such as canonical correlation analysis or redundancy discriminant analysis. As a result, the spectral separability of the vegetation units is improved and the vegetation units are accurately mapped (overall accuracy $>85 \%$, kappa index > 0.78) (Oldeland et al. 2010; Middleton et al. 2012). However, the ecological consistency of the vegetation units mapped is altered. In fact, several plant communities with a similar physiognomy or biomass are merged into the same vegetation unit. At best, these vegetation units may be related to broad vegetation classes (e.g. "Sparse grassland and open patches"; "Eutrophic fen") but in no way correspond to meaningful plant communities sensu stricto, i.e. typology of the plant associations (Bioret et al. 2013).

2. Several recent studies have investigated the contribution of multispectral satellite data time series. For example, semi-natural grasslands were accurately mapped (overall accuracy $>$ 80\%) using RapidEye (Schmidt et al. 2014) or Sentinel-2A (Shoko \& 
Mutanga 2017) multispectral time series. However, only the dominant vegetation patches were distinguished due to the relatively coarse spatial resolution of these time series $(6-10 \mathrm{~m})$, which is insufficient to identify patches of small, long or thin plant communities (Roth et al. 2015). Another study highlighted the contribution of TerraSAR-X time series to accurate mapping of 7 grassland habitats (overall accuracy 90\%, kappa index 0.89) with a $2 \mathrm{~m}$ spatial resolution (Schuster et al. 2015). However, these SAR time series remain expensive.

3. Other studies have focused on mapping the floristic continuum rather than mapping plant communities. For example, the floristic continuum was mapped with high accuracy $\left(\mathrm{r}^{2}>0.8\right)$ using airborne hyperspectral imagery of raised-bog (Schmidtlein et al. 2007) or heath habitats (Neumann et al. 2015). In addition, Feilhauer et al. (2014) successfully mapped local variability in complex mire habitats using Rapideye and Sentinel-2 simulated multispectral imagery $\left(r^{2}>0.7\right.$, overall accuracy 0.71$)$. However, these promising approaches are not yet operational for wide use to report the requirements of Habitat Directive in natural habitats as they have been developed for specific environments, such as raised bogs, mires or heaths covering a few hectares; lower accuracy was observed when mapping dry heaths and pioneer grassland habitats (Neumann et al. 2015).

4. A well-known approach for dealing with uncertainty is the fuzzy approach (Zadeh 1965). Unlike the widely applied crisp approaches, the fuzzy approach assigns a probability of membership in each class to each individual. This property is useful for addressing floristic and spectral uncertainty and assessing the confidence level of the classification of a given plant community to one or more spectral response(s). Until now, the fuzzy approach has been applied widely to classify vegetation relevés (De Cáceres et al. 2010; Wiser \& Cáceres 2013; Duff et al. 2014) or remote sensing data. 
For example, Zlinszky et al. $(2014 ; 2015)$ mapped herbaceous habitats with $68 \%$ and $62 \%$ overall accuracy, respectively (kappa index 0.64 and 0.58 , respectively), using point-cloud LiDAR data. But the combined use of fuzzy classification based on both vegetation and remote sensing data still remains to be investigated (Rocchini 2014).

The objective of this study was to accurately map grassland plant communities using a comprehensive fuzzy approach in order to address the floristic and spectral uncertainty. To do this, we first created a vegetation typology that is both ecologically and spectrally consistent in terms of performing a dimensional scaling of the floristic and spectral values derived from vegetation relevés and remote sensing data, respectively. Second, we mapped grassland plant communities using the noise clustering classifier. The strengths and weaknesses of the methodology proposed will be discussed below.

\section{Material and methods}

\subsection{Study area}

The study site, a large area spanning $73 \mathrm{~km}^{2}$ in a Natura 2000 site, is the second largest French wetland area, located in the Poitevin marsh, close to the French Atlantic coast $\left(46.4^{\circ} \mathrm{N}, 1.2^{\circ} \mathrm{W}\right)($ Fig. 1$)$. The climate is oceanic temperate, with a mean monthly minimum/maximum temperature ranging from $2 / 10^{\circ} \mathrm{C}$ in winter to $12 / 24^{\circ} \mathrm{C}$ in summer. The annual mean precipitation ranges from 700 to $900 \mathrm{~mm}$ with a summer water deficit. Coming from a successive embankment since the $10^{\text {th }}$ century, this marsh has a relatively flat geomorphology with slight depressions. The elevation ranges between 1.5 and $3.5 \mathrm{~m}$ above sea level. The grasslands are extensively grazed or mown. They are composed of sub-brackish herbaceous plant communities, driven by a flooding pattern (Amiaud et al. 1998) and grazing pattern (Marion et al. 2010), that correspond to Natura 2000 class 1410.3 (thermo-Atlantic 


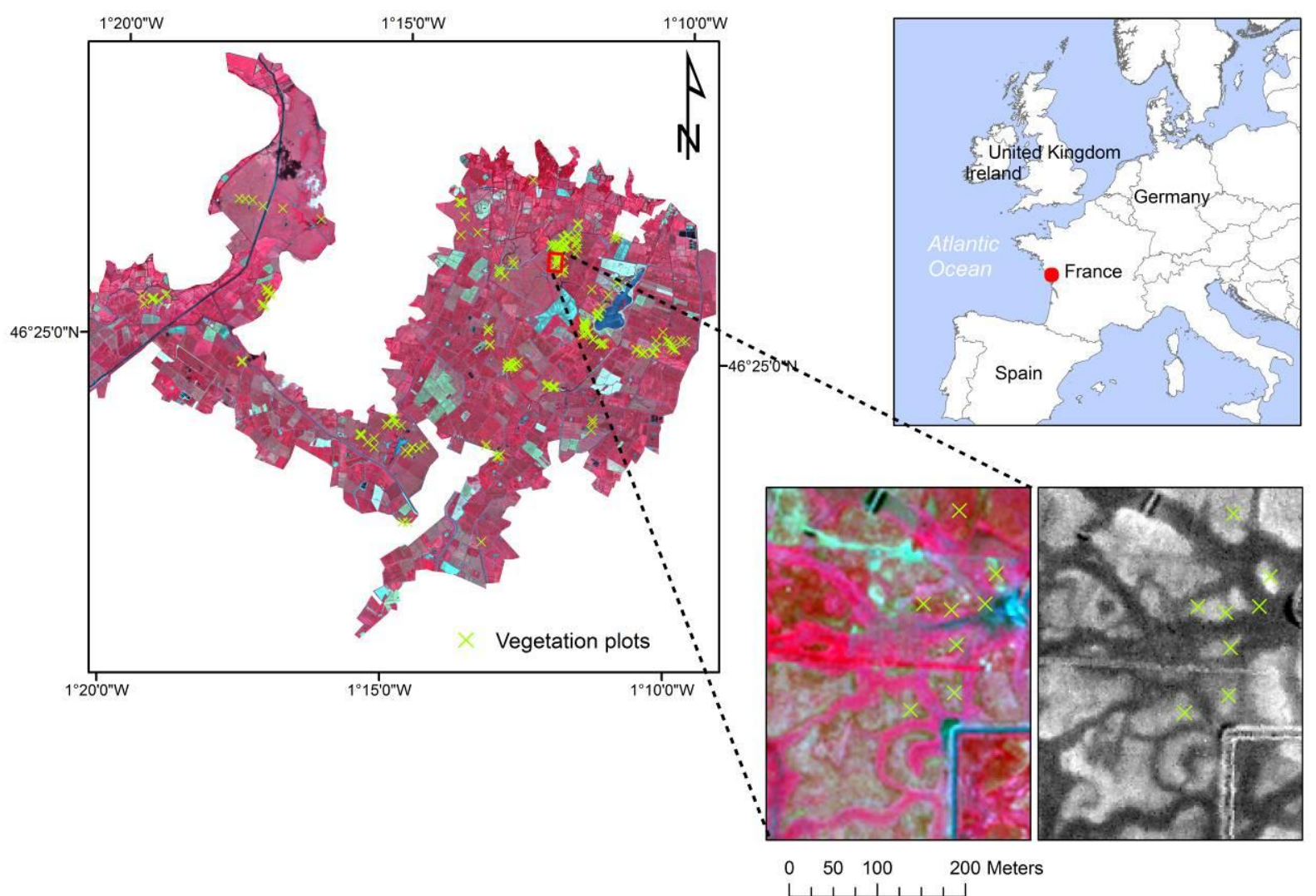

Fig. 1. Study site and vegetation plot location. False-colour composite of a Pléiades image (@ CNES ISIS) located in the Poitevin marsh (France). The inserts show a subset of the grassland pattern on the Pléiades image (left) and the LiDAR-derived Digital Terrain Model (right). 


\section{FUZZY CLASSIFICATION OF VEGETATION RELEVÉS}

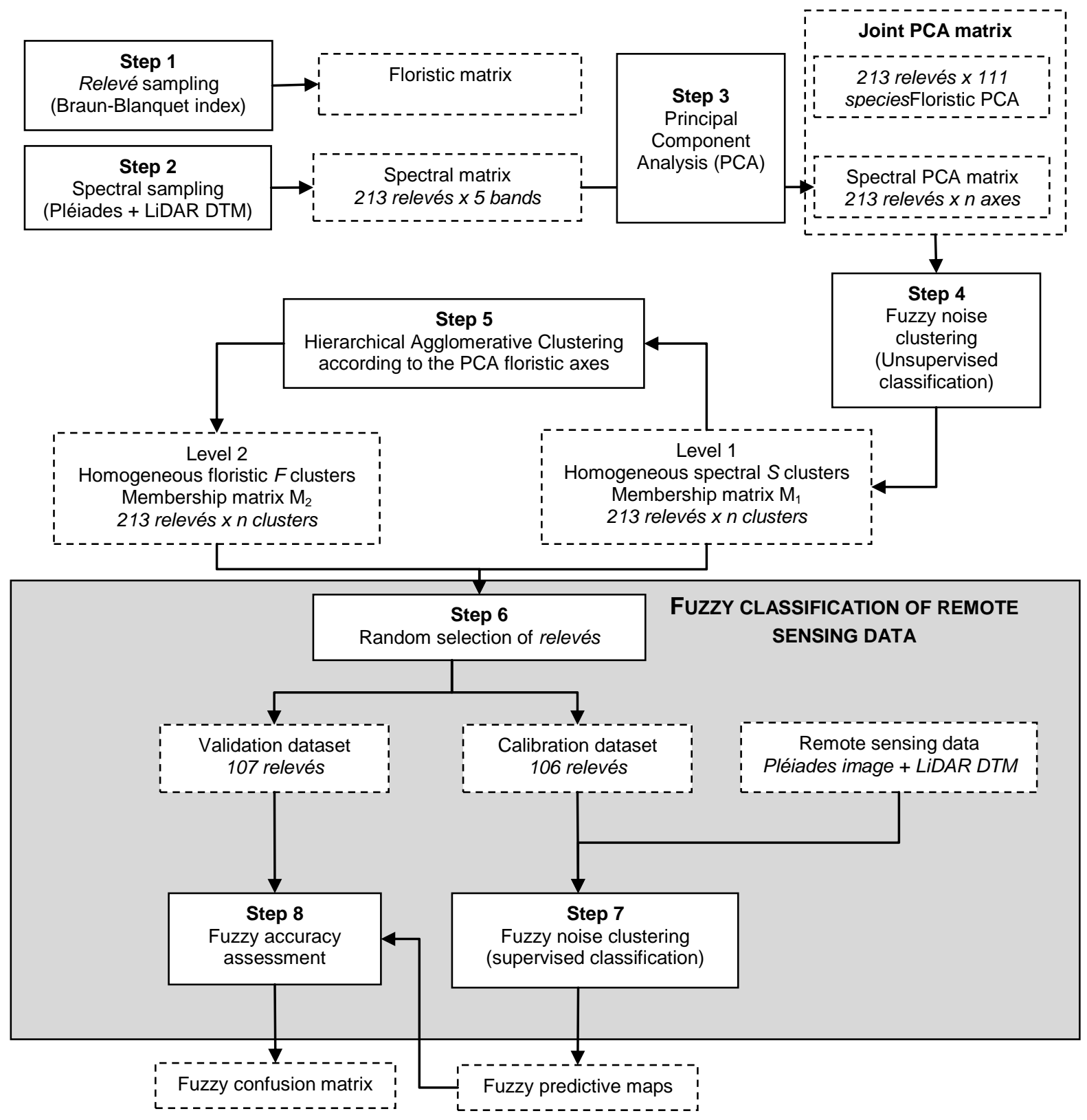

Fig. 2. Methodological flowchart detailing the comprehensive fuzzy approach. First (top), relevés were classified using a fuzzy noise clustering classifier; then (bottom), this fuzzy model was predicted from remote sensing data. 


\subsubsection{Step 1. Vegetation relevé sampling}

167 Due to the spatial resolution of the Pléiades imagery (2 m), we selected vegetation relevés 168 within a $6 \mathrm{~m} \times 6 \mathrm{~m}$ quadrat to avoid mixed pixels. Vegetation relevés were collected in the 169 field from May to June 2015. To stratify the field sampling, unsupervised classification (20 classes) was performed on a Pléiades satellite image acquired in May 2013. This 20-class map was loaded in the field computer and helped us to identify main spatial patterns within grasslands. Following the traditional phytosociological rule (Dengler 2017), relevés were collected within plots with a priori homogeneous floristic composition. For each vegetation relevé, the number of vascular plant species was recorded ( $n=111$ for all plots) and their abundance was estimated using the Braun-Blanquet approach (Braun-Blanquet 1932). In total, 220 vegetation relevés were geo-referenced using a differential GPS (error $<0.5 \mathrm{~m}$ ) and recorded in the vegetation database TURBOVEG (Hennekens \& Schaminée 2001).

\subsubsection{Step 2. Spectral sampling}

This step associates vegetation relevés with reflectance spectra extracted from remote sensing data. A multispectral Pléiades image was used in combination with LiDAR (Light Detection and Ranging) data. We used a multispectral Pléiades image because it presents a good tradeoff between cost $\left(€ 1 / \mathrm{km}^{2}\right)$, spatial resolution and coverage $(15 \mathrm{~km} \times 15 \mathrm{~km})$. The Pléiades image (@ CNES ISIS program) was acquired in June 2014 and features a high spatial resolution $(2 \mathrm{~m})$ with 12-bit depth spectral information in the blue $(443-550 \mathrm{~nm})$, green $(490$ $610 \mathrm{~nm})$, red (590-710 $\mathrm{nm})$ and near infrared $(740-940 \mathrm{~nm})$ regions. The Pléiades image was delivered at Level-1B, which includes inter-detector normalization, inter-array reconstruction and geometric corrections (Panem et al. 2012). The image was orthorectified using a LiDAR Digital Terrain Model (DTM). The horizontal error of the rectified image was less than 1 pixel. The Pléiades image was atmospherically corrected using the MODTRAN-4 model (Adler-Golden et al. 1999). In addition, we integrated a LiDAR DTM in the vegetation 
modelling as vegetation strongly responds to elevation contrasts (Moeslund et al. 2011;

Rapinel et al. 2015; Alexander et al. 2016). Airborne LiDAR data were acquired in November 2011 by the French Mapping Agency (IGN - Institut Géographique National). Only the LiDAR-derived DTM was subsequently delivered (grid size $1 \mathrm{~m}$, vertical accuracy $0.2 \mathrm{~m}$ ); the raw point cloud was unavailable. Although some topographical variables such as the Topographic Wetness Index (TWI) and Topographic Position Index (TPI) have been relevant for mapping plant communities in wetlands (Alexander et al. 2016), we did not use them because 1- the TWI is not suited for wetlands such as the Marais Poitevin, in which anthropogenic features such as pipes and ditches have altered natural hydrological runoff (Lindsay \& Dhun 2015); and 2- the TPI - which expresses elevation relative to that of the stream is scale-dependent (Alexander et al. 2016). To address these concerns, we chose to express elevation as the depression elevation (Alber \& Piégay 2011).This DTM was modified to be expressed relative to the depression elevation instead of the sea level by subtracting the absolute value of the DTM from the altimetric reference plan corresponding to the local depression slope (see Alber \& Piégay (2011) for a detailed description of the methodology). The reflectance spectra associated with the vegetation relevés were taken from the Pléiades image and the modified DTM. Then, the values of the pixels included within each vegetation relevé were averaged. To avoid ambiguities between ground data and remote sensing imagery, we verified the homogeneity of the Pléiades spectral responses when calculating the Euclidean distance between the spectra within each vegetation relevé. Seven heterogeneous vegetation relevés were removed, leaving 213 plots for the analysis.

\subsection{Creation of a typology using the vegetation relevés}

\subsubsection{Step 3. Independent PCA applied to the floristic matrix and spectral matrix}

This step builds a "joint" matrix that includes both spectral and floristic dimensionallyreduced data. Many studies have shown the interest of unconstrained ordination such as a 
principal component analysis (PCA) to summarize the floristic variance (Legendre \& Gallagher 2001). The main advantage of the PCA method compared to the non-metric multidimensional scaling (NMDS) method is that a difference between the abundance values for a common species contributes more to the distance than the same difference for a rare species, so that rare species may have a limited influence on the analysis. Therefore, the PCA method is better suited to our dataset because plant communities are more likely to differ by a variation in the abundances of the dominant species rather than the occurrence of rare species. As a preprocess, the Braun-Blanquet cover values on floristic data were replaced with the median cover values of each class $(1=0.03 ; 2=0.13 ; 3=0.375 ; 4=0.625 ; 5=0.875)$ in order to linearize the cover values. Then, the cover values were submitted to a Chord transformation (i.e. divided by the norm). These transformations must be done before performing a PCA on this type of floristic dataset to ensure that the Euclidean distances between the vegetation relevés calculated from the plant cover values accurately reflect the floristic similarities between the relevés (Legendre \& Gallagher 2001). We performed two distinct PCAs: a first PCA on the floristic data and a second PCA on the spectral data. As the floristic and spectral matrices have completely different value ranges, each dataset was scaled separately using centered scaling before PCA. Last, we built a "joint" PCA matrix with the $n$ axes scores of the floristic PCA and the $n$ axes scores of the spectral PCA.

\subsubsection{Step 4. Fuzzy noise clustering (unsupervised classification)}

This step classifies vegetation relevés into spectrally separable clusters with a fuzzy approach. In vegetation science, a fuzzy classification recognizes that certain vegetation relevés may correspond to a transition between many plant communities and as a result, they could have an uncertain classification. The joint PCA matrix was used as basis for the unsupervised fuzzy classification of the vegetation relevés. As the joint PCA matrix contains data from both floristic and spectral PCA, the unsupervised classification should cluster relevés that share 
both floristic and spectral similarities. We used a noise clustering classifier (NC) (De Cáceres et al. 2010), a prototype-based clustering method derived from the C-means (Bezdek et al. 1984), to find $c$ clusters and assign $n$ plots to these $c$ clusters so that the resulting clusters are compact and distinct from each another. The NC classifier results in a fuzzy classification because a cluster membership probability is assigned to each vegetation relevé where the sum of the membership probabilities is equal to 1 . The NC classifier also identifies "noise" relevés resulting from rare spectral or floristic values. The advantage is that "noise" relevés do not affect the cluster centers. Hence, the centers of interest are ultimately more distinct from each other (De Caceres 2016). The main input parameters for the NC algorithm are the number of clusters created by the method $(m C)$, the fuzziness coefficient $(m)$ and the distance to the noise cluster $(\delta)$. A high $m$ value will lead to a classification where the probabilities of belonging to a cluster are more distributed over several clusters while a low $\delta$ value will increase the number of plots attributed to the noise cluster. Based on preliminary tests performed on our dataset, we set the intervals of input parameters as follows: $m C$ 15-30 using a step of 1, $m$ 1.1-1.9 using a step of 0.1 and $\delta 1.5-2.0$ using a step of 0.1. After completing the fuzzy classification process, we called $M_{l}$ the resulting membership matrix that gives, for each vegetation relevé, the respective probabilities of belonging to the different spectrally homogeneous $S$ clusters, i.e. one with low spectral variance.

\subsubsection{Step 5. Hierarchical agglomerative clustering}

This step groups the spectrally homogeneous clusters into floristically homogeneous clusters.

Level 1 corresponds to the spectrally homogeneous S clusters (i.e. with low spectral variability within clusters). They were derived from the NC classifier of the joint PCA matrix but with classifier parameters that minimized spectral variability to the detriment of floristic variability. The higher Level 2 corresponds to the floristically homogeneous F clusters (i.e. with low floristic variability within clusters) that were derived from the initial Level 1 clusters 
merged with hierarchical agglomerative clustering based on floristic PCA axes. Here, we hypothesized that a given plant community (Level 2) may have several distinct spectral signatures (Level 1). For this reason, it is important to first identify spectrally homogeneous clusters discernible on remote sensing data. The main input parameter for HAC is the threshold value, which determines the final number of clusters. As a result, a second membership matrix $M_{2}$ containing the probabilities of belonging to the F clusters (Level 2) was created by summing the membership probabilities of the agglomerated $\mathrm{S}$ clusters (Level 1) from $M_{1}$. Expert-based assignment was then applied between the floristically homogeneous F clusters (Level 2) and the French phytosociological system (Bioret et al. 2013).

\subsubsection{Search for optimal clustering parameters}

In order to find the best clustering parameter values ( $m C, m, \delta, H A C$ threshold), we carried out a major tuning procedure that repeated steps 3-5 with different combinations of the parameter values. Our objective was to find an optimal trade-off classification for the vegetation relevés that respects three criteria: 1- having homogeneous spectral clusters at $M_{l}$, 2- having homogeneous floristic clusters at $M_{2}$ and 3- having at least $60 \%$ of the vegetation relevés classified with a maximum membership higher than 0.4 . The homogeneous spectral clustering was assessed based on two geometric indices - the average silhouette value (Rousseeuw 1987), which geometrically evaluates the quality of the clustering, and Hubert's C-index (Hubert \& Arabie 1985), which compares the partition obtained with the best partition that could have been obtained with this number of groups and this distance matrix. The homogeneous floristic clustering was assessed based on an ecological index, the fidelity coefficient phi (Chytrý et al. 2002) (only species with phi $\geq 0.2$ were considered as diagnostic species), in combination with average silhouette value and Hubert's C-index. The average silhouette value and Hubert's C-index assess whether the clusters are compact and distinct 
from each other while the phi coefficient specifically assesses whether a cluster contains diagnostic species, which are crucial for identifying vegetation units (De Cáceres et al. 2015).

The optimal clustering parameters were determined to correspond to the maximum (for the average silhouette value and number of diagnostic species) and minimum values (for Hubert's C-index) of three selected indices and should result in the best trade-off classification of the vegetation relevés with regards to their homogeneous spectral and floristic clusters.

\subsection{Fuzzy classification of remotely sensed data}

\subsubsection{Step 6. Random selection of the relevés}

This step randomly assigns each relevé to the calibration or validation dataset. In the supervised classification of RS data, all relevés, including noise relevés, were used. The classified vegetation relevés were equally and randomly split into two datasets: 1- the calibration dataset used for the supervised NC classifier and 2- the validation dataset used to assess the accuracy of the classified remote sensing data. Both calibration and validation datasets included the $M_{1}$ and $M_{2}$ matrices.

\subsubsection{Step 7. Fuzzy noise clustering (supervised classification)}

This step applies the noise clustering model to all pixels of the remote sensing image. Usually, the field samples used to classify remote sensing data have a crisp assignment to a single cluster. Here, we assume that a vegetation relevé has a probability of belonging to each cluster. For this reason, the remote sensing data were classified using the NC, which preserves the fuzzy assignment of the vegetation relevés (see step 4). A supervised classification of remotely sensed data was performed using the homogeneous spectral matrix $M_{l}$ in the calibration dataset. The classification produced a membership matrix $C M_{1}$ giving, for each pixel, its probabilities of belonging to each homogeneous spectral cluster. Then, the memberships of $C M_{l}$ were summed based on the aggregation rules defined in the HAC 
analysis (step 5). This resulted in a $C M_{2}$ matrix giving, for each pixel, its probabilities of belonging to each homogeneous floristic cluster. At the end of the classification procedure, a set of fuzzy maps was produced for each vegetation cluster. To obtain a crisp map of the vegetation cluster based on crisp classification, the membership matrix $\mathrm{CM}_{2}$ was defuzzified by attributing, to each pixel, the class for which it had the highest membership probability. In addition, two other classes were considered: 1 - the noise class, generated by the NC classifier and composed of the outliers, and 2 - the unclassified class, corresponding to pixels with a maximum $C M_{2}$ membership probability less than 0.4 (below which there is no clear majority among clusters).

\subsubsection{Step 8. Fuzzy accuracy assessment}

This step measures the accuracy of the fuzzy classification of the remote sensing image. The traditional crisp calculation of the confusion matrix requires the defuzzification of the fuzzy map. To avoid losing membership information, we chose to calculate a fuzzy confusion matrix from the fuzzy predicted and reference membership matrices following Binaghi et al. (1999). Finally, a fuzzy kappa was calculated using Cohen's kappa coefficient to measure the agreement between the fuzzy sets proposed by (Dou et al. 2007). Details of the calculations are given in Appendix S1. Relevés with a maximum membership probability less than 0.4 among the 9 vegetation clusters were considered "unclassified". However, their membership probabilities were included when calculating the confusion matrix. To compare accuracy results to those of a traditional crisp classifier, relevés' membership probability for the noise class was not considered when assessing the accuracy.

To avoid any bias due to the selection of the calibration and validation data, the remotely sensed data classification procedure (from step 6 to step 8) was repeated 1000 times with randomly selected calibration and validation datasets. The classification with the median overall accuracy value was selected as the final fuzzy classification output. 


\subsection{Assessment of the fuzzy noise clustering approach}

341 In order to assess the relevance of our approach to existing ones, we compared the overall 342 accuracy of the vegetation maps derived from: (i) a fuzzy and a crisp classification, (ii) our 343 "trade-off" typology with a floristic typology on the one hand and a physiognomic typology on the other hand. Crisp classification of the remote sensing data was performed using the crisp vegetation dataset (by defuzzifing the $M_{2}$ membership matrix, i.e. assigning each relevé to a vegetation cluster based on its highest membership probability) with a support vector machine (SVM) algorithm that is widely recognized as the most efficient classifier (Mountrakis et al. 2011). The optimal calibration model was defined by a 10 -fold crossvalidation sampling method. The floristic typology was constructed based on the scores of the floristic PCA axes. Conversely, the physiognomic typology was based on the score of the spectral PCA axes.

All analyses were performed in the R 3.1.2 statistical environment (R Core Team 2015) using the packages vegan (v 2.3-4) (Oksanen et al. 2015), vegclust (v 1.6.3) (De Caceres 2016), ade4 (v 1.7-4) (Dray \& Dufour 2007), raster (v 2.5-2) (Hijmans 2015) and rgdal (v 1.1-3) (Bivand et al. 2015).

\section{Results}

\subsection{Classification of the vegetation relevés}

The numbers of dimensions considered in the floristic and spectral PCA, respectively, were set to three for each PCA. As a result, the NC classification was performed on PCA matrix $M_{l}$ which contained six variables explaining $38.1 \%$ and $97.8 \%$ of the floristic and spectral 
cluster $(\delta=1.7)$ values were quite large with the result that $35.2 \%$ and $2.3 \%$ of the total plots

364 fell into the unclassified (i.e. maximum class membership < 0.4) and noise clusters, respectively. The number of initial clusters was set to $m C=15$ for $M_{1}$ and merged to form nine final clusters $\left(M_{2}\right)$ after the agglomerative hierarchical clustering $(d t=0.6)$.

367 Figure 3 clearly illustrates the weak relationship between the spectral and floristic variance and the interest of the nested-level approach: at level 1, the S clusters had similar spectral values (average silhouette value $=0.15$ ) but quite different floristic values with a high intraclass variance (average silhouette value $=0.10$ ). Conversely at level 2 , the F clusters had

371 similar floristic values (average silhouette value $=0.21$; Hubert's $\mathrm{C}$ index $=0.12$ ) and were 372 characterized by at least one diagnostic species $(n=56)$ but had quite different spectral values 373 (average silhouette value $=-0.02$ ). As an example, at level 1, clusters S6 and S11 had similar 374 floristic values that overlap (Fig. 3, upper right) but which could be clearly distinguished by 375 their clear spectral differences (Fig. 3, upper left). At level 2, these two clusters were merged 376 together into a F6 cluster with similar floristic values (Fig. 3, bottom right) but with spectral 377 values spread out between clusters F2 and F5. Dendrogram and silhouette plots are presented Appendix S2. 

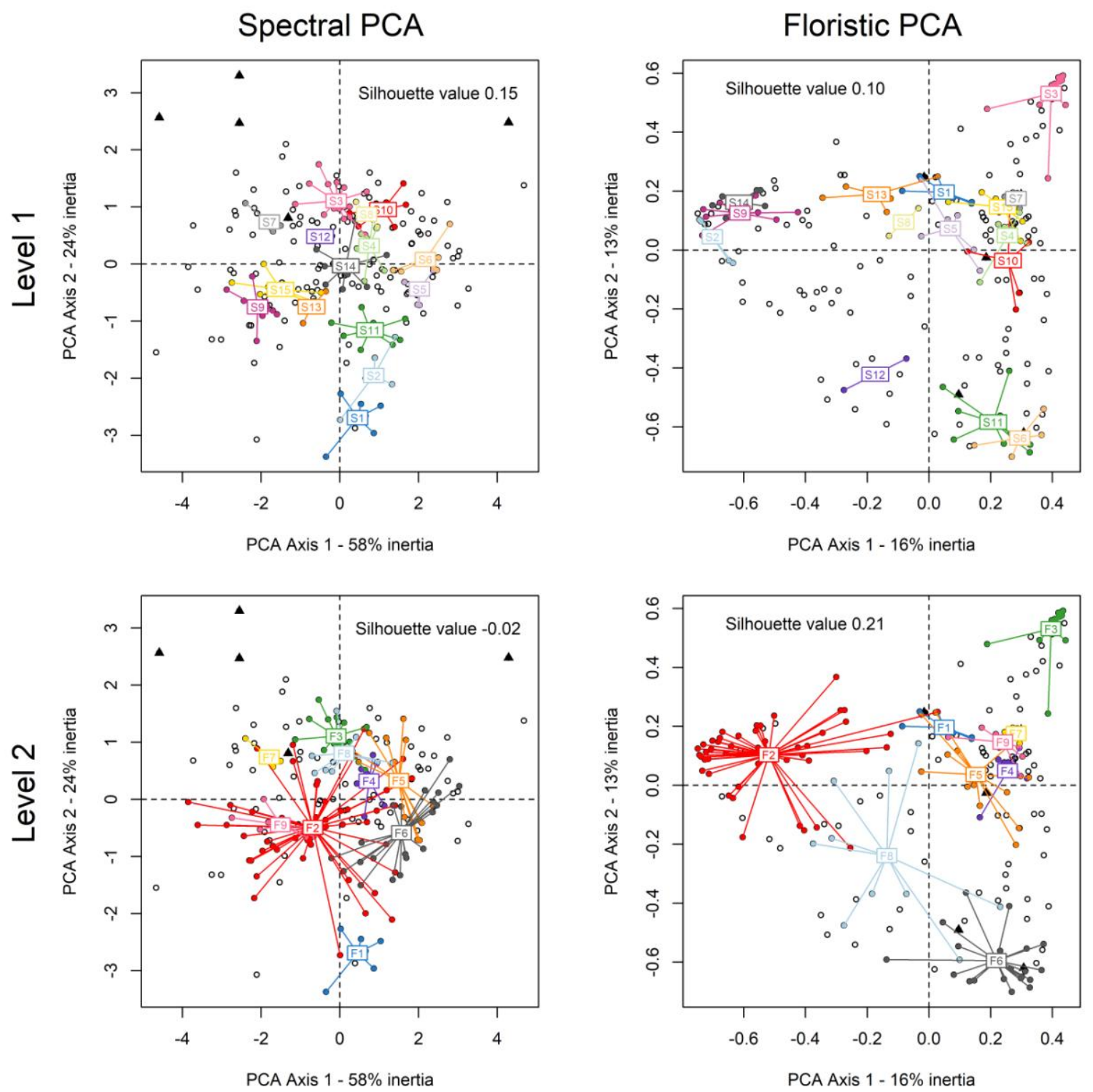

○ transitional relevés (class membership <0.4) $\Delta$ noise relevés

Fig. 3. Weak relationship between spectral and floristic variance and the utility of the nested-level approach. For visualization purposes, scaled principal component analyses (PCA) were performed at level 1 (top) and level 2 (bottom) on the spectral (left) and floristic (right) values. Each cluster derived from noise clustering of the joint PCA matrix is represented by a code and a colour.

The floristic composition of each final cluster together with the number of initial clusters are

shown in Table 1. Correspondence with the French national nomenclature is also provided 
cluster F1 is related to the Urtico dioicae-Phalaridetum arundinaceae plant community while cluster F2 corresponds to the Eleocharito palustris-Oenanthetum fistulosae plant community variation at Ranunculus ophioglossifolius. Cluster F3 is related to meso-hygrophilious (annual flood duration between 1 and 3 months) and grazed grasslands corresponding to the Alopecuro bulbosi-Juncetum gerardii plant community. Cluster F4 is related to mesohygrophilious grasslands with alternative grazing and mowing corresponding to the Trifolio maritimi-Oenanthetum silaifoliae plant community. Clusters F5 and F6 are related to mesohygrophilious and mown grasslands corresponding respectively to the Junco gerardiOenanthetum fistulosae and Elytrigio repentis-Caricetum divisae plant communities. Clusters F7 and F8 are very similar and correspond to mesophilious (annual flood duration $<1$ month) and grazed grasslands related to the Carici divisae-Lolietum perennis plant community. Cluster F8 is found on more intensively grazed grasslands. Cluster F9 is found in mesophilous grasslands with alternative grazing and mowing phases and corresponds to the Hordeo secalini-Lolietum perennis plant community.

Notably, four clusters (F2, F5, F6 and F8) are characterized by two or more spectral signatures (S clusters, level 1) while five other clusters (F1, F3, F4, F7 and F9) are characterized by one spectral signature (Table 1). 
Table 1. Synoptic table of the vegetation units in the Poitevin marsh. Frequency values (in percentages) of the species in the clusters obtained from the noise clustering classifier. Diagnostic species are indicated in gray (phi $\geq 0.20$ ) and dark gray ( $\mathrm{phi} \geq 0.40$ ). The full version is available in Appendix S3.

\begin{tabular}{|c|c|c|c|c|c|c|c|c|c|}
\hline \multirow{3}{*}{\begin{tabular}{|l|} 
DOMINANT AGRICULTURAL PRACTICES \\
ANNUAL FLOOD DURATION \\
CLUSTER NAME (LEVEL 2) \\
\end{tabular}} & \multicolumn{3}{|c|}{ Grazing } & \multicolumn{3}{|c|}{ Mowing } & \multirow{2}{*}{\multicolumn{3}{|c|}{$\begin{array}{c}\text { Grazing } \\
<1 \text { month }\end{array}$}} \\
\hline & \multicolumn{2}{|c|}{4 months } & \multicolumn{4}{|c|}{ 1-3 months } & & & \\
\hline & $\mathrm{F} 1$ & $\mathrm{~F} 2$ & $\mathrm{~F} 3$ & $\mathrm{~F} 4$ & F5 & F6 & F7 & F8 & F9 \\
\hline NUMBER OF INITIAL CLUSTERS (LEVEL 1) & 1 & 4 & 1 & 1 & 2 & 2 & 1 & 2 & 1 \\
\hline Eleocharis uniglumis & 43 & 8 & & & & & & & \\
\hline Phalaris arundinacea & 29 & 3 & & & & 5 & & & \\
\hline Agrostis stolonifera & 57 & 97 & 7 & 29 & 46 & 50 & 20 & 100 & 38 \\
\hline Glyceria fluitans & 43 & 46 & & & 8 & & & & \\
\hline Oenanthe fistulosa & 29 & 74 & & & 8 & 55 & & & 38 \\
\hline Ranunculus repens & 14 & 59 & & & 15 & 10 & 20 & & \\
\hline Eleocharis palustris & 57 & 49 & & & 15 & 5 & & & \\
\hline Mentha pulegium & 14 & 41 & & & 15 & 5 & & & \\
\hline Trifolium fragiferum & 14 & 46 & 7 & & 15 & & & & 38 \\
\hline Hordeum marinum & & 3 & 87 & & 8 & & 20 & & \\
\hline Juncus gerardi & & 8 & 100 & & 23 & 25 & 40 & 20 & 13 \\
\hline Parapholis strigose & & & 47 & & & & & & \\
\hline Plantago coronopus & & & 87 & & 23 & & 60 & 10 & \\
\hline Holcus lanatus & & 5 & & 100 & 31 & 25 & & 10 & 25 \\
\hline Festuca arundinacea & & 3 & & 29 & & 10 & & & \\
\hline Tragopogon porrifolius & & & & 29 & & & & & \\
\hline Medicago littoralis & & & & 29 & & & & & \\
\hline Trifolium pratense & & & & 43 & & & & & 13 \\
\hline Trifolium maritimum & & & 20 & 86 & 54 & 25 & 100 & 20 & \\
\hline Anthoxanthum odoratum & & 3 & & 71 & 54 & 20 & & 30 & 13 \\
\hline Elytrigia repens & & 21 & 20 & 29 & 77 & 100 & 20 & 90 & 38 \\
\hline Carex divisa & & 15 & 53 & 71 & 62 & 95 & 40 & 100 & 13 \\
\hline Leontodon hispidus & & & & & & & 60 & & \\
\hline Trifolium subterraneum & & & & & & & 40 & & 25 \\
\hline Hypochaeris radicata & & & & 14 & & & 40 & 10 & 13 \\
\hline Iris spuria & & & & & & & & 40 & \\
\hline Bromus racemosus & & & 27 & 29 & 8 & & 40 & 70 & 25 \\
\hline Cynosurus cristatus & & & & 43 & 31 & 10 & 80 & 80 & 38 \\
\hline Cirsium species & & & & & & & & 20 & \\
\hline Hordeum secalinum & 14 & 23 & 20 & 43 & 46 & 10 & 20 & 80 & 63 \\
\hline Lolium perenne & & 5 & 20 & 43 & 38 & 5 & 100 & 70 & 100 \\
\hline Trifolium repens & & & & 14 & 8 & & & 10 & 38 \\
\hline Ranunculus acris & & 3 & & & & & & & 50 \\
\hline
\end{tabular}




\subsection{Classification of remotely sensed data}

408 The supervised fuzzy noise clustering classification of remotely sensed data produced three 409 sets of maps: class membership maps for each plant community (Fig. 4, left), an uncertainty

410 map (Fig. 4, right) and a crisp classification map (Appendix S5). To improve visualization of

411 the fuzzy classification, class membership maps for each plant community were featured

412 using hue-preserving colour blending (Chuang et al. 2009). The main advantages are that each

413 vegetation cluster has a specific colour and that the colour's saturation level indicates the

414 certainty of class assignment (Zlinszky \& Kania 2016). The spatial distribution of grassland

415 habitats along wetlands is consistent with their ecological preferendum: for example, cluster

416 F2 is clearly distributed in topographical depressions and long-term flood areas while clusters

$417 \quad$ F7 and F8 occur at higher elevations that are rarely flooded. Notably, cluster F3 is linearly

418 distributed along topographical slopes. Interestingly, the map of the noise cluster highlights

419 non-grassland habitats such as channels, crops and bare soils but also noisy pixels such as tree

420 shadows and flooded vegetation. The uncertainty map reveals transitional areas between two

421 plant communities. 

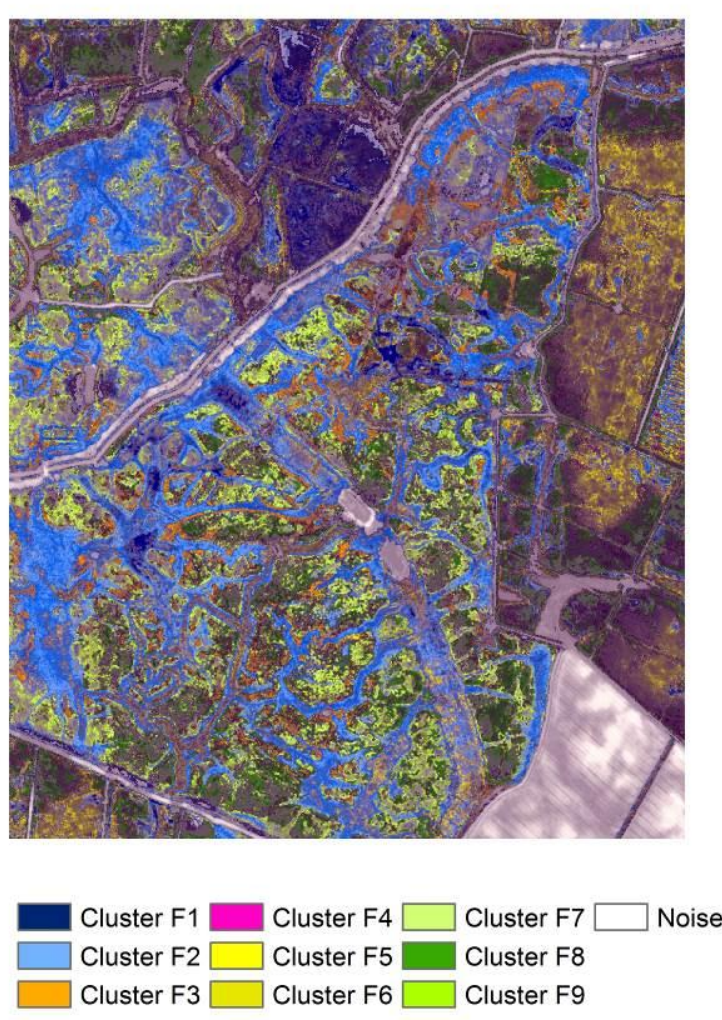
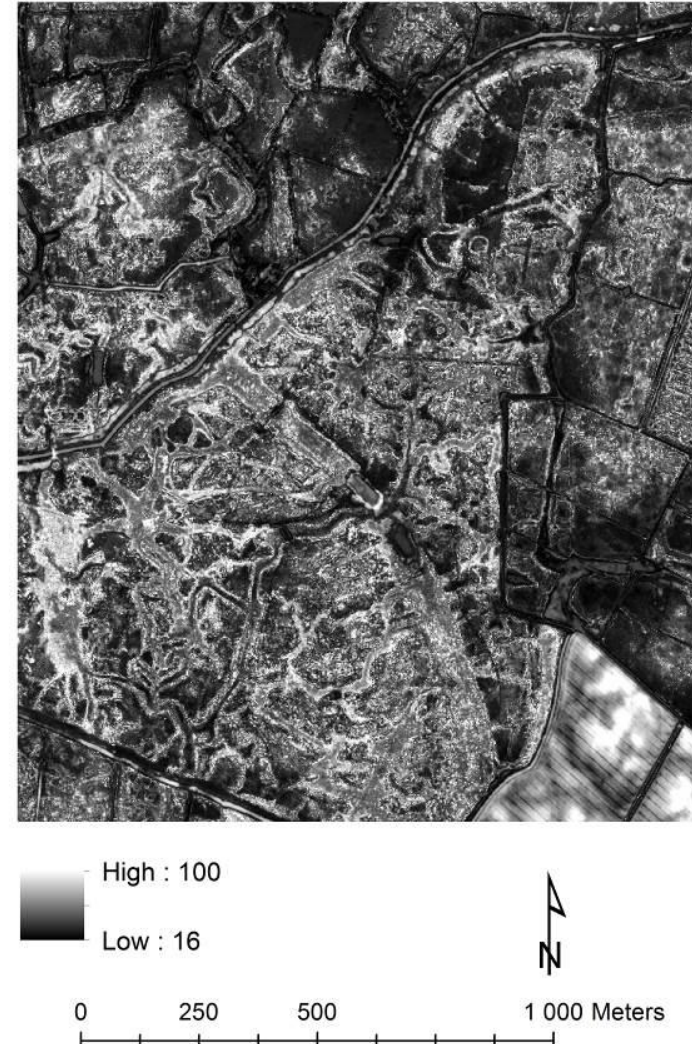

Fig. 4. Subset of classified vegetation maps derived from the fuzzy noise clustering: the fuzzy blended image (left) using the hue-preserving algorithm (see Zlinszky and Kania (2016)) shows gradual transitions between classes; the uncertainty image (right) shows areas of high uncertainty in black and more certain areas in white.

423 The iterative process of random selection of calibration and validation dataset shows low

424 variation in overall accuracy (standard deviation $=1.7$ ). The median fuzzy confusion matrix

425 shows an overall accuracy of $62 \%$ (Table 2). The producer's accuracy values are higher than

$42660 \%$ for all clusters except for clusters F3, F4 and F9. The user's accuracy values are higher

427 than $60 \%$ for all clusters, except for clusters F1, F6 and F9. The reference and classified

428 membership matrices are available in Appendix S4. The importance of spectral bands to

429 classification accuracy is detailed in Appendix S6. 
Table 2. Fuzzy accuracy assessment of the map of plant communities derived from remote sensing imagery: overall accuracy (\%), Kappa index, producer's accuracy (\%) and user's accuracy (\%) for each cluster.

\begin{tabular}{|c|l|c|c|}
\hline Cluster & \multicolumn{1}{|c|}{ Plant community } & $\begin{array}{c}\text { Producer's } \\
\text { Accuracy }\end{array}$ & $\begin{array}{c}\text { User's } \\
\text { Accuracy }\end{array}$ \\
\hline F1 & Urtico dioicae - Phalaridetum arundinaceae & 60 & 57 \\
\hline F2 & $\begin{array}{l}\text { Eleocharito palustris-Oenanthetum fistulosae variation at Ranunculus } \\
\text { ophioglossifolius }\end{array}$ & 69 & 60 \\
\hline F3 & Alopecuro bulbosi-Juncetum gerardii & 56 & 60 \\
\hline F4 & Trifolio maritimi-Oenanthetum silaifoliae & 43 & 65 \\
\hline F5 & Junco gerardi - Oenanthetum fistulosae & 67 & 61 \\
\hline F6 & Elytrigio repentis-Caricetum divisae & 65 & 63 \\
\hline F7 & $\begin{array}{l}\text { Carici divisae-Lolietum perennis variation at Plantago coronopus and } \\
\text { Bellis perennis }\end{array}$ & 68 & 68 \\
\hline F8 & Carici divisae-Lolietum perennis & 40 & 25 \\
\hline F9 & Hordeo secalini-Lolietum perennis & & 62 \\
\hline
\end{tabular}

\subsection{Impact of the typology and fuzzy approach on map accuracy}

The influence of our trade-off typology and fuzzy approach on map accuracy is presented in

Fig. 5. It highlights a clear trade-off between the overall accuracy of the classification and the

floristic significance of the typology. When the floristic typology is applied (Fig. 5, left), the overall accuracy of the classification is excellent either with a fuzzy $(92.8 \%)$ or crisp $(90.6 \%)$ classification approach but the clusters have quite different floristic values (average silhouette

442 value $=-0.03$ ). Using the compromise typology (Fig. 5, middle), the clusters are not only comprised of similar floristic values (average silhouette value $=0.21$ ) but they also contain distinct spectral values (overall accuracy $=62 \%$ ) when a fuzzy classification is performed. In 


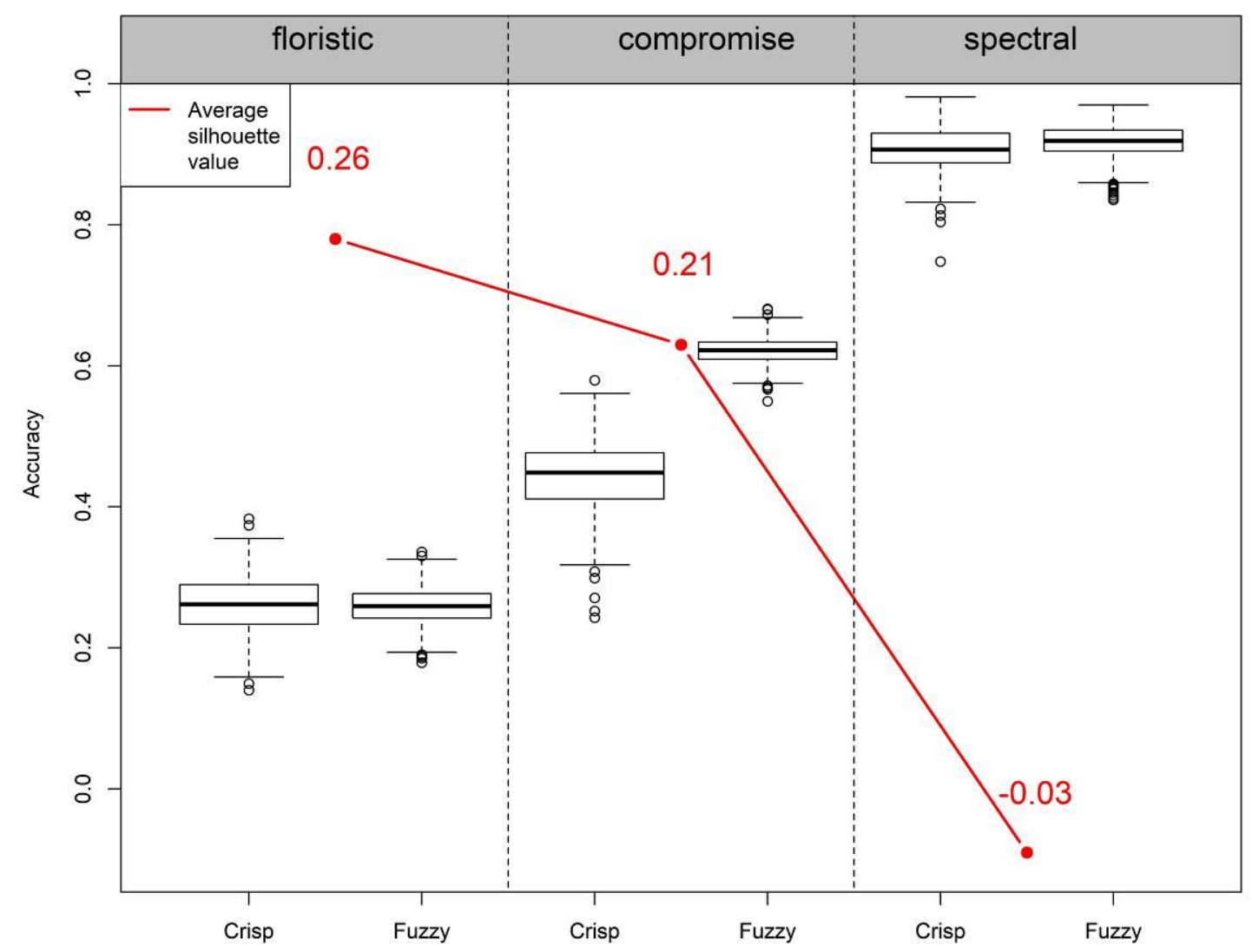

Fig. 5. Trade-off between mapping accuracy (expressed as the overall accuracy percentage) and floristic coherence of the typology (expressed as the average silhouette value). Boxplots were calculated from 1000 iterations of random selection of calibration and validation relevés.

\section{Discussion}

449 The aim of this study was to map grassland plant communities on a large wetland site (73

$450 \mathrm{~km}^{2}$ ) combining a cost-effective satellite multispectral image and a LiDAR-derived DTM. We

451 developed a novel approach that combines a compromise typology and a fuzzy approach. The

452 grassland plant communities were classified and mapped with 62\% accuracy (kappa index

453 0.56), which is acceptable considering the area of the study site, the detailed typology (9 
clusters, each representing a grassland with a similar physiognomy) and the inexpensive remote sensing data used. In comparison, Kumar and Sinha (2014) achieved an accuracy of $42 \%$ using satellite multispectral imagery on a $9.5 \mathrm{~km}^{2}$ salt marsh; Roelofsen et al. (2014) achieved an accuracy of 59\% (kappa index 0.46) using airborne hyperspectral imagery alone on a $12 \mathrm{~km}^{2}$ coastal marsh and Zlinszky et al. $(2014 ; 2015)$ mapped herbaceous habitats with $68 \%$ and $62 \%$ overall accuracy, respectively (kappa index 0.64 and 0.58 , respectively), using point-cloud LiDAR data of meadows covering a few hectares. The maps we produced appear to reliably detect and report on plant communities. It provides a valuable source of data to assess and monitor the conservation status of natural habitats. Together with trait-based maps (Lausch et al. 2016), this type of floristically-sensitive vegetation map will open up new avenues for documenting habitat-related ecosystem services.

\subsection{Significance of method used to develop the typology}

We aimed to develop a vegetation typology that is both ecologically and spectrally consistent

(Fig. 5). Given the weak relationship between spectral variance - derived from inexpensive multispectral imagery - and floristic composition, a trade-off between the floristic significance of the clusters and the classification accuracy of the RS data should be taken into account. As already pointed out (Thomas et al. 2003; Kumar \& Sinha 2014; Martínez-López et al. 2014), a solely floristic-based typology produced an inaccurate classification of remote sensing data ( $25-40 \%)$. To address this issue, a common approach is to aggregate plant communities into vegetation formations such as lawns, sedges, poor fens, bogs, shrubs and woods (Thomas et al. 2003; Middleton et al. 2012); open dwarf shrub, sparse grassland, and woody acacia shrub (Oldeland et al. 2010) or mangrove, pasture, dry grass, and salt-marsh vegetation (Kumar \& Sinha 2014). One of the two main advances of our study is to show that hybrid distance in a multivariate space combining the PCA scores of spectral and floristic data produced a "compromise" typology - identifying 9 grassland plant communities, each with a 
similar physiognomy - that could be accurately mapped. Figure 6 clearly shows that compared to the floristic typology - the compromise typology strongly improved RS classification by 36 points (from $26 \%$ to $62 \%$ ) while preserving the homogeneous floristic clusters (the average silhouette value decreased slightly from 0.26 to 0.21 ).

Besides, both plant communities and dominant species can be mapped from hyperspectral imagery (Schmidtlein et al. 2007), LiDAR point clouds (Zlinszky et al. 2014) or TerraSAR-X time series (Schuster et al. 2015), but their high cost limits their use. Therefore, one of the main results of the method was to establish a correspondence between our vegetation units and the French national reference for natural habitats (Bioret et al. 2013). In this study, correspondences between clusters and syntaxonomy units were based on expert-based assignments because the French phytosociological system is not yet stabilized. In the near future, an improved version of the system will be available based on the VegFrance database, which includes digital relevés (Bonis \& Bouzillé 2012) and the use of numerical approaches (Tichý et al. 2014).

Several improvements to the development of the typology can be suggested. It should be recalled that spectral clusters (i.e. canopy reflectance) vary over time (Feilhauer et al. 2016), as do floristic clusters. To transfer this approach to other sites, satellite images should be acquired during the optimal period: from maximum development of herbaceous vegetation to the beginning of mowing. This issue can also be addressed by analyzing annual satellite time series to examine dynamics of the spectral response of vegetation over time (Schuster et al. 2015; Shoko \& Mutanga 2017). Besides, the use of NMDS scaling would result in all of the floristic variance being found on either two or three axes (Schmidtlein et al. 2007; Feilhauer et al. 2014) compared with only $38 \%$ of the floristic variance, as observed in the PCA we used in the present study. However, NMDS axes should be carefully interpreted as a function of the stress value (Clarke 1993). Moreover, NMDS scaling may be influenced by rare species, 
which may lead to incorrect interpretations (Legendre \& Gallagher 2001). Indeed, preliminary tests we performed on the dataset showed that PCA produced a clearer pattern than NMDS due to two "outlier" relevés dominated by Phragmites australis and Phalaris arundinacea species. The second issue is related to the definition of the number of clusters. In this study, the reliability of the clusters was assessed with average silhouette value, the number of diagnostic species and Hubert' C-indexes, usually used in vegetation science for phytosciological classifications (Douda et al. 2016); however, the effectiveness of the silhouette method is still an open question (Dengler et al. 2013). Otherwise, the set of field data upon which the classification of the nine clusters is based consists of 213 plots. In the near future, it will be useful to check this using more plots. In this regard, the national vegetation data base is a promising tool (Bonis \& Bouzillé 2012).

\subsection{Contribution of the fuzzy approach}

This study highlights that the integration of floristic and spectral uncertainty by using a fuzzy approach increased the accuracy of a vegetation map by $17 \%$ (Fig. 5). The comprehensive fuzzy approach we have developed includes: 1-the fuzzy classification of vegetation data, 2the fuzzy classification of remote sensing data and 3-the fuzzy accuracy assessment of the resulting map. This approach can be used to consider both the floristic and spectral uncertainty over the entire analysis, something that has been identified as an important challenge of vegetation mapping (Rocchini 2014). When the comprehensive fuzzy approach is not used, the remote-sensing data classification may be biased by an arbitrary expert-based typology. Thus, it seems that the fuzzy approach is needed to map natural habitats, specifically those in wetlands where subtle variations in topography and pasturage have a fine-grained pattern, with progressive transitions between habitats (Dumont et al. 2012); in the present study, 35\% of relevés were not clearly assigned to a vegetation unit (Figure 3). As a result, the uncertainty map (Figure 4) contains many uncertain pixels (in black), which can 
be viewed initially as an obstacle to direct operational use. However, the uncertain pixels also highlight target areas where additional field relevés are needed (Zlinszky \& Kania 2016).

Before analysis, we ensured that relevés were floristically and spectrally homogeneous to avoid ambiguities between ground data and remote sensing imagery. This common preliminary step is essential to remove relevés with spurious spectral values, such as those associated with the presence of clouds or cows (e.g. see Schmidtlein et al. (2007) or Schmidtlein et al. (2012)). It was all the more necessary as spectral values of pixels were averaged per relevé; in this sense, we consider that the fuzzy approach addresses uncertainty between relevés but not within them. In our sampling design, only 7 of the 220 relevés were discarded $(<2 \%$ of the total), because of spectral heterogeneity explained by shallow water on part of the plot.

Many widely used supervised classifiers, such as support vector machine or random forest, initially produce fuzzy outcomes before a final crisp classification. Several studies have shown the contribution of such classifiers to fuzzy mapping of grassland habitats (Zlinszky et al. 2014; Zlinszky \& Kania 2016). In this study, we applied a noise-clustering classifier twice: first as an unsupervised classifier to classify the pixels corresponding to vegetation relevés and then as a supervised classifier to classify all the pixels in the image.

\subsection{The potential of cost-effective remote sensing data}

In this study, we opted for a cost-effective multispectral Pléiades satellite image $\left(€ 1 / \mathrm{km}^{2}\right)$ and free national LiDAR-derived DTM rather than expensive RS data. The combined use of one Pléiades image and a LiDAR-derived DTM resulted in a classification accuracy of $62 \%$. In accordance with (Feilhauer et al. 2013; Chasmer et al. 2014), we pointed out that LiDAR DTM and near infrared spectra were important variables to discriminate natural habitats in wetlands (Appendix S6). Specifically, the contribution of LiDAR DTM (+5\% in overall 
accuracy) corroborates previous studies highlighting the strong relationship between plant community distribution and micro-topography in wetlands (Moeslund et al. 2011; Alexander et al. 2016). It should be kept in mind, however, that this relationship can be biased locally by water management such as intensive drainage for agriculture or, conversely, water retention for conservation (Rapinel et al. 2018). Beyond 2-D LiDAR variables, many studies (Zlinszky et al. 2014; Zlinszky et al. 2015) have also highlighted the contribution of 3-D variables such as echo width, intensity response and surface roughness to accurately map grassland habitats (overall accuracy 62-68\%, kappa index 0.57-0.64). In this sense, combining multispectral satellite imagery with point-cloud LiDAR data is a promising avenue for mapping plant communities. The mapping accuracy may be slightly increased $( \pm 10 \%)$ with other costeffective multispectral satellite imagery such as RapidEye or SPOT-5, which feature additional red edge and SWIR spectral bands, respectively, and which have been shown to be relevant to accurately map wetland natural habitats (Davranche et al. 2010; Stenzel et al. 2014). Until now, accuracy greater than $85 \%$ could be reached only by using airborne hyperspectral (Burai et al. 2015) ; hyperspatial resolution imagery from an unmanned aerial vehicle (Kaneko \& Nohara 2014) or full-waveform LiDAR data (Launeau et al. 2018) of small sites covering several hectares. However, the new Sentinel time-series with a high spatial resolution $(10 \mathrm{~m})$ seem promising to accurately map natural habitats, using Sentinel-1 SAR (Schmidt et al. 2017) or Sentinel-2 multispectral (Shoko \& Mutanga 2017) sensors. Such time-series satellite images, which are both free and cost-effective, are now available and appear promising to accurately distinguish between plant communities in the near future.

Considering that the spectral response is partially linked to species composition as well as to physiognomy, litter thickness, biomass and abiotic variables such as proportion of bare soil and water content (Feilhauer et al. 2013), we hypothesized that a plant community may show several spectral signatures. Our results confirmed this hypothesis as four clusters were 
characterized by at least two spectral signatures. Specifically, cluster L2, corresponding to a grazed hygrophilous plant community, has four spectral signatures. In wetland environments, the presence of water in different proportions may explain this spectral variability from plant community clusters, as highlighted in some Australian salt marshes (Kumar \& Sinha 2014). Future field campaigns with systematic measurements of the plant species composition combined with biomass and abiotic variables could be used to explain the relationship between the spectral responses and floristic composition, as done by Feilhauer et al. (2013).

\subsection{A new way to monitor habitats for the UE Directive}

Using RS data for application of the EU Habitats Directive has been emphasized for a decade (Vanden Borre et al. 2011). Most RS studies, however, have focused on the Natura 2000 nomenclature (e.g. Alexandridis et al. 2009; Stenzel et al. 2014; Féret et al. 2015) rather than on plant communities, which are the "elementary" units of biodiversity (Pott 2011). Rodwell et al. (2018) and Bioret et al. (2017) recently urged clarifying the actual object of Natura 2000 reporting and the need to consider elementary habitats (i.e. plant communities). The approach we developed, which was able to map 9 plant communities as "elementary" habitats, opens avenues to do so. It should kept in mind that these elementary habitats form the basis of the Natura 2000, CORINE and EUNIS nomenclatures, "though this involvement has been complex and unclear" (Rodwell et al. 2018). Here, we used RS data to map 9 "elementary" habitats that are included in the "thermo-Atlantic and sub-brackish meadows" Natura 2000 habitat, which encompasses diverse and even contrary environmental conditions caused by environmental management such as flood duration (from less than 1 month for Hordeo secalini-Lolietum perennis up to 4 months for Eleocharito palustris-Oenanthetum fistulosae) and agricultural practices (grazing for Carici divisae-Lolietum perennis or mowing for Junco gerardi-Oenanthetum fistulosae). From a structural perspective, each "elementary" habitat that we mapped could be used as a surrogate of a species pool (Zlinszky et al. 2015) but also 
of species richness, stand structural diversity or key species cover (Neumann et al. 2015;

Schmidt et al. 2017). From a functional perspective, these "elementary" habitats - which are ecologically homogeneous units - could also provide insights into their corresponding environmental conditions as well as their functional traits (e.g. seed mass), which are indirectly detectable from RS data (Violle et al. 2011).

One challenge of applying the Habitats Directive is the field sampling effort. In accordance with Zlinszky \& Kania (2016), we believe that the fuzzy map with hue-preserving blending provides a more realistic view of the complex spatial patterns of natural vegetation and highlights transitional areas between habitats as well as uncertain areas (Fig. 4). This fuzzy map provides useful and new guidelines to local managers for planning additional field relevés and strengthening collaborations between remote sensing and ecologist communities (Vanden Borre et al. 2011).

\section{Conclusion}

The comprehensive fuzzy procedure successfully mapped herbaceous plant communities at the ecosystem scale using inexpensive remote sensing data. Floristic and spectral uncertainty was considered in a fuzzy approach, resulting in the mapping of 9 herbaceous plant communities with acceptable accuracy. As the natural habitats were characterized at the plant community level, correspondence with functional properties of the species or with ecosystem services can be easily inferred. These encouraging results open up new ways to meet the requirements for monitoring the conservation status of natural habitats in the EU Habitats Directive

\section{Acknowledgements}

We are grateful to the French Ministry of Ecology - CarHab program - for funding the research (Contract No. 2100992719). The authors would like to thank the ISIS program of the 
French Space Agency (CNES) and the French Geographical Institute (IGN) for providing the

628

629

630

631

632

633

634

635

636

637

638

639

640

641

642

643

644

645

646

647

648

649

650

651

652

653

654

655

656

657

658

659

Pléiades imagery and LiDAR data. We thank Johan Oszwald for preliminary discussions on

this project and methodological advice and Adam Kania for processing the hue-preserving

blending algorithm. We also thank Olivier Jambon, Valérie Gouesbet, Guillaume Bouger,

Pauline Herbert and Olivier Gore for their help in the field and all land owners and managers

who gave us access to their fields and provided useful discussions.

\section{References}

Adler-Golden, S.M., Matthew, M.W., Bernstein, L.S., Levine, R.Y., Berk, A., Richtsmeier, S.C., Acharya, P.K., Anderson, G.P., Felde, J.W., Gardner, J.A., Hoke, M.L., Jeong, L.S., Pukall, B., Ratkowski, A.J., \& Burke, H.K. 1999. Atmospheric correction for shortwave spectral imagery based on MODTRAN4. In pp. 61-69.

Alber, A., \& Piégay, H. 2011. Spatial disaggregation and aggregation procedures for characterizing fluvial features at the network-scale: Application to the Rhône basin (France). Geomorphology 125: 343-360.

Alexander, C., Deák, B., \& Heilmeier, H. 2016. Micro-topography driven vegetation patterns in open mosaic landscapes. Ecological Indicators 60: 906-920.

Alexandridis, T.K., Lazaridou, E., Tsirika, A., \& Zalidis, G.C. 2009. Using Earth Observation to update a Natura 2000 habitat map for a wetland in Greece. Journal of Environmental Management 90: 2243-2251.

Ali, I., Cawkwell, F., Dwyer, E., Barrett, B., \& Green, S. 2016. Satellite remote sensing of grasslands: from observation to management. Journal of Plant Ecology 9: 649-671.

Amiaud, B., Bouzillé, J.-B., Tournade, F., \& Bonis, A. 1998. Spatial patterns of soil salinities in old embanked marshlands in western France. Wetlands 18: 482-494.

Berg, C., Abdank, A., Isermann, M., Jansen, F., Timmermann, T., \& Dengler, J. 2014. Red Lists and conservation prioritization of plant communities - a methodological framework. Applied Vegetation Science 17: 504-515.

Bezdek, J.C., Ehrlich, R., \& Full, W. 1984. FCM: The fuzzy c-means clustering algorithm. Computers \& Geosciences 10: 191-203.

Binaghi, E., Brivio, P.A., Ghezzi, P., \& Rampini, A. 1999. A fuzzy set-based accuracy assessment of soft classification. Pattern Recognition Letters 20: 935-948.

Bioret, F., Capelo, J., \& Pedrotti, F. 2017. À propos de la cartographie des habitats d'intérêt communautaire de la Directive européenne Habitats FauneFlore 92/43/CE. Documents Phytosociologiques 6: 447-451. 
Bioret, F., Gaudillat, V., \& Royer, J.M. 2013. The Prodrome of French vegetation: a national synsystem for phytosociological knowledge and management issues. Plant sociology 50: 17-21.

Bivand, R., Keitt, T., \& Rowlingson, B. 2015. rgdal: Bindings for the Geospatial Data Abstraction Library.

Bonis, A., \& Bouzillé, J. aB. 2012. The project VegFrance: Towards a national vegetation database for France. Plant Sociology 49: 97a99.

Braun-Blanquet, J. 1932. Plant Sociology. The study of plant communities. Plant sociology. The study of plant communities. First ed.

Burai, P., Deák, B., Valkó, O., \& Tomor, T. 2015. Classification of Herbaceous Vegetation Using Airborne Hyperspectral Imagery. Remote Sensing 7: 2046-2066.

Chasmer, L., Hopkinson, C., Veness, T., Quinton, W., \& Baltzer, J. 2014. A decision-tree classification for low-lying complex land cover types within the zone of discontinuous permafrost. Remote Sensing of Environment 143: 73-84.

Chuang, J., Weiskopf, D., \& Moller, T. 2009. Hue-Preserving Color Blending. IEEE Transactions on Visualization and Computer Graphics 15: 1275-1282.

Chytrý, M., Tichý, L., Holt, J., \& Botta-Dukát, Z. 2002. Determination of diagnostic species with statistical fidelity measures. Journal of Vegetation Science 13: 79-90.

Clarke, K.R. 1993. Non-parametric multivariate analyses of changes in community structure. Austral ecology 18: 117-143.

Corbane, C., Lang, S., Pipkins, K., Alleaume, S., Deshayes, M., García Millán, V.E., Strasser, T., Vanden Borre, J., Toon, S., \& Michael, F. 2015. Remote sensing for mapping natural habitats and their conservation status - New opportunities and challenges. International Journal of Applied Earth Observation and Geoinformation 37: 7-16.

Davranche, A., Lefebvre, G., \& Poulin, B. 2010. Wetland monitoring using classification trees and SPOT-5 seasonal time series. Remote Sensing of Environment 114: 552-562.

De Caceres, M. 2016. Package 'vegclust.'

De Cáceres, M., Chytrý, M., Agrillo, E., Attorre, F., Botta-Dukát, Z., Capelo, J., Czúcz, B., Dengler, J., Ewald, J., Faber-Langendoen, D., Feoli, E., Franklin, S.B., Gavilán, R., Gillet, F., Jansen, F., Jiménez-Alfaro, B., Krestov, P., Landucci, F., Lengyel, A., Loidi, J., Mucina, L., Peet, R.K., Roberts, D.W., Roleček, J., Schaminée, J.H.J., Schmidtlein, S., Theurillat, J.-P., Tichý, L., Walker, D.A., Wildi, O., Willner, W., Wiser, S.K., \& Scheiner, S. 2015. A comparative framework for broad-scale plot-based vegetation classification. Applied Vegetation Science 18: 543-560.

De Cáceres, M., Font, X., \& Oliva, F. 2010. The management of vegetation classifications with fuzzy clustering. Journal of Vegetation Science 21: 1138-1151.

Dengler, J. 2017. Phytosociology. In International Encyclopedia of Geography, pp. 1-6. American Cancer Society. 
Dengler, J., Bergmeier, E., Willner, W., \& Chytrý, M. 2013. Towards a consistent classification of European grasslands. Applied Vegetation Science 16: 518-520.

Dou, W., Ren, Y., Wu, Q., Ruan, S., Chen, Y., Bloyet, D., \& Constans, J.-M. 2007. Fuzzy kappa for the agreement measure of fuzzy classifications. Neurocomputing 70: 726-734.

Douda, J., Boublík, K., Slezák, M., Biurrun, I., Nociar, J., Havrdová, A., Doudová, J., Aćić, S., Brisse, H., Brunet, J., Chytrý, M., Claessens, H., Csiky, J., Didukh, Y., Dimopoulos, P., Dullinger, S., FitzPatrick, Ú., Guisan, A., Horchler, P.J., Hrivnák, R., Jandt, U., Kącki, Z., Kevey, B., Landucci, F., Lecomte, H., Lenoir, J., Paal, J., Paternoster, D., Pauli, H., Pielech, R., Rodwell, J.S., Roelandt, B., Svenning, J.-C., Šibík, J., Šilc, U., Škvorc, Ž., Tsiripidis, I., Tzonev, R.T., Wohlgemuth, T., \& Zimmermann, N.E. 2016. Vegetation classification and biogeography of European floodplain forests and alder carrs. Applied Vegetation Science 19: 147-163.

Dray, S., \& Dufour, A.-B. 2007. The ade4 package: implementing the duality diagram for ecologists. Journal of statistical software 22: 1-20.

Duff, T.J., Bell, T.L., \& York, A. 2014. Recognising fuzzy vegetation pattern: the spatial prediction of floristically defined fuzzy communities using species distribution modelling methods. Journal of Vegetation Science 25: 323-337.

Dumont, B., Rossignol, N., Loucougaray, G., Carrère, P., Chadoeuf, J., Fleurance, G., Bonis, A., Farruggia, A., Gaucherand, S., Ginane, C., Louault, F., Marion, B., Mesléard, F., \& Yavercovski, N. 2012. When does grazing generate stable vegetation patterns in temperate pastures? Agriculture, Ecosystems \& Environment 153: 50-56.

Feilhauer, H., Dahlke, C., Doktor, D., Lausch, A., Schmidtlein, S., Schulz, G., \& Stenzel, S. 2014. Mapping the local variability of Natura 2000 habitats with remote sensing. Applied Vegetation Science 17: 765-779.

Feilhauer, H., Somers, B., \& van der Linden, S. 2016. Optical trait indicators for remote sensing of plant species composition: Predictive power and seasonal variability. Ecological Indicators

Feilhauer, H., Thonfeld, F., Faude, U., He, K.S., Rocchini, D., \& Schmidtlein, S. 2013. Assessing floristic composition with multispectral sensors-A comparison based on monotemporal and multiseasonal field spectra. International Journal of Applied Earth Observation and Geoinformation 21: 218-229.

Féret, J.B., Corbane, C., \& Alleaume, S. 2015. Detecting the Phenology and Discriminating Mediterranean Natural Habitats With Multispectral Sensors \#x2014;An Analysis Based on Multiseasonal Field Spectra. IEEE Journal of Selected Topics in Applied Earth Observations and Remote Sensing 8: 2294-2305.

Gargominy, O., Tercerie, S., Daszkiewicz, P., Régnier, C., Ramage, T., Dupont, P., \& Poncet, L. 2012. TAXREF v5. 0 , référentiel taxonomique pour la France: mise en œuuvre et diffusion. SPN, Paris.

Hennekens, S.M., \& Schaminée, J.H.J. 2001. TURBOVEG, a comprehensive data base management system for vegetation data. Journal of Vegetation Science 12: 589-591.

Hijmans, R.J. 2015. raster: Geographic Data Analysis and Modeling.

Hubert, L., \& Arabie, P. 1985. Comparing partitions. Journal of Classification 2: 193-218. 
Kaneko, K., \& Nohara, S. 2014. Review of effective vegetation mapping using the UAV (Unmanned Aerial Vehicle) method. Journal of Geographic Information System 6: 733.

Kumar, L., \& Sinha, P. 2014. Mapping salt-marsh land-cover vegetation using high-spatial and hyperspectral satellite data to assist wetland inventory. GIScience \& remote sensing 51: 483497.

Lang, S., Mairota, P., Pernkopf, L., \& Schioppa, E.P. 2015. Earth observation for habitat mapping and biodiversity monitoring. International Journal of Applied Earth Observation and Geoinformation 37: 1-6.

Launeau, P., Giraud, M., Ba, A., Moussaoui, S., Robin, M., Debaine, F., Lague, D., \& Le Menn, E. 2018. Full-Waveform LiDAR Pixel Analysis for Low-Growing Vegetation Mapping of Coastal Foredunes in Western France. Remote Sensing 10: 669.

Lausch, A., Bannehr, L., Beckmann, M., Boehm, C., Feilhauer, H., Hacker, J., Heurich, M., Jung, A., Klenke, R., Neumann, C., \& others. 2016. Linking Earth Observation and taxonomic, structural and functional biodiversity: Local to ecosystem perspectives. Ecological Indicators 70: 317339.

Lavorel, S., Grigulis, K., Lamarque, P., Colace, M.-P., Garden, D., Girel, J., Pellet, G., \& Douzet, R. 2011. Using plant functional traits to understand the landscape distribution of multiple ecosystem services. Journal of Ecology 99: 135-147.

Legendre, P., \& Gallagher, E.D. 2001. Ecologically meaningful transformations for ordination of species data. Oecologia 129: 271-280.

Lindsay, J., \& Dhun, K. 2015. Modelling surface drainage patterns in altered landscapes using LiDAR. International Journal of Geographical Information Science 29: 397-411.

Marion, B., Bonis, A., \& Bouzillé, J.-B. 2010. How Much does Grazing-Induced Heterogeneity Impact Plant Diversity in Wet Grasslands? Ecoscience 17: 229-239.

Martínez-López, J., Carreño, M.F., Palazón-Ferrando, J.A., Martínez-Fernández, J., \& Esteve, M.A. 2014. Remote sensing of plant communities as a tool for assessing the condition of semiarid Mediterranean saline wetlands in agricultural catchments. International Journal of Applied Earth Observation and Geoinformation 26: 193-204.

Middleton, M., Närhi, P., Arkimaa, H., Hyvönen, E., Kuosmanen, V., Treitz, P., \& Sutinen, R. 2012. Ordination and hyperspectral remote sensing approach to classify peatland biotopes along soil moisture and fertility gradients. Remote Sensing of Environment 124: 596-609.

Moeslund, J.E., Arge, L., Bøcher, P.K., Nygaard, B., \& Svenning, J.-C. 2011. Geographically Comprehensive Assessment of Salt-Meadow Vegetation-Elevation Relations Using LiDAR. Wetlands 31: 471-482.

Mountrakis, G., Im, J., \& Ogole, C. 2011. Support vector machines in remote sensing: A review. ISPRS Journal of Photogrammetry and Remote Sensing 66: 247-259.

Neumann, C., Weiss, G., Schmidtlein, S., Itzerott, S., Lausch, A., Doktor, D., \& Brell, M. 2015. GradientBased Assessment of Habitat Quality for Spectral Ecosystem Monitoring. Remote Sensing 7: 2871-2898. 
Oksanen, J., Blanchet, F.G., Kindt, R., Legendre, P., Minchin, P.R., O'Hara, R.B., Simpson, G.L., Solymos, P., Stevens, M.H.H., \& Wagner, H. 2015. vegan: Community Ecology Package.

Oldeland, J., Dorigo, W., Lieckfeld, L., Lucieer, A., \& Jürgens, N. 2010. Combining vegetation indices, constrained ordination and fuzzy classification for mapping semi-natural vegetation units from hyperspectral imagery. Remote Sensing of Environment 114: 1155-1166.

Panem, C., Bignalet-Cazalet, F., \& Baillarin, S. 2012. Pleiades-HR system products performance after in-orbit commissioning phase. ISPRS-International Archives of the Photogrammetry, Remote Sensing and Spatial Information Sciences 39: 567-572.

Peeters, A. 2009. Importance, evolution, environmental impact and future challenges of grasslands and grassland-based systems in Europe. Grassland Science 55: 113-125.

Pott, R. 2011. Phytosociology: A modern geobotanical method. Plant Biosystems - An International Journal Dealing with all Aspects of Plant Biology 145: 9-18.

Rapinel, S., Dusseux, P., Bouzillé, J.-B., Bonis, A., Lalanne, A., \& Hubert-Moy, L. 2018. Structural and functional mapping of geosigmeta in Atlantic coastal marshes (France) using a satellite time series. Plant Biosystems - An International Journal Dealing with all Aspects of Plant Biology. doi: 10.1080/11263504.2017.1418447

Rapinel, S., Hubert-Moy, L., \& Clément, B. 2015. Combined use of LiDAR data and multispectral earth observation imagery for wetland habitat mapping. International Journal of Applied Earth Observation and Geoinformation 37: 56-64.

Rocchini, D. 2014. Fuzzy species distribution models: a way to represent plant communities spatially. Journal of Vegetation Science 25: 317-318.

Rocchini, D., Boyd, D.S., Féret, J.-B., Foody, G.M., He, K.S., Lausch, A., Nagendra, H., Wegmann, M., \& Pettorelli, N. 2016. Satellite remote sensing to monitor species diversity: potential and pitfalls. Remote Sensing in Ecology and Conservation 2: 25-36.

Rocchini, D., \& Cade, B.S. 2008. Quantile Regression Applied to Spectral Distance Decay. IEEE Geoscience and Remote Sensing Letters 5: 640-643.

Rocchini, D., Foody, G.M., Nagendra, H., Ricotta, C., Anand, M., He, K.S., Amici, V., Kleinschmit, B., Förster, M., Schmidtlein, S., Feilhauer, H., Ghisla, A., Metz, M., \& Neteler, M. 2013. Uncertainty in ecosystem mapping by remote sensing. Computers \& Geosciences 50: 128135.

Rodwell, J.S., Evans, D., \& Schaminée, J.H.J. 2018. Phytosociological relationships in European Union policy-related habitat classifications. Rendiconti Lincei. Scienze Fisiche e Naturali. doi: 10.1007/s12210-018-0690-y

Roelofsen, H.D., Kooistra, L., van Bodegom, P.M., Verrelst, J., Krol, J., \& Witte, J.-P.M. 2014. Mapping a priori defined plant associations using remotely sensed vegetation characteristics. Remote Sensing of Environment 140: 639-651.

Roth, K.L., Roberts, D.A., Dennison, P.E., Peterson, S.H., \& Alonzo, M. 2015. The impact of spatial resolution on the classification of plant species and functional types within imaging spectrometer data. Remote Sensing of Environment 171: 45-57. 
Rousseeuw, P.J. 1987. Silhouettes: A graphical aid to the interpretation and validation of cluster analysis. Journal of Computational and Applied Mathematics 20: 53-65.

Schmidt, J., Fassnacht, F.E., Förster, M., \& Schmidtlein, S. 2017. Synergetic use of Sentinel-1 and Sentinel-2 for assessments of heathland conservation status. Remote Sensing in Ecology and Conservation

Schmidt, T., Schuster, C., Kleinschmit, B., \& Förster, M. 2014. Evaluating an Intra-Annual Time Series for Grassland Classification \#x2014; How Many Acquisitions and What Seasonal Origin Are Optimal? IEEE Journal of Selected Topics in Applied Earth Observations and Remote Sensing 7: 3428-3439.

Schmidtlein, S., Feilhauer, H., \& Bruelheide, H. 2012. Mapping plant strategy types using remote sensing. Journal of Vegetation Science 23: 395-405.

Schmidtlein, S., Zimmermann, P., Schüpferling, R., \& Weiß, C. 2007. Mapping the floristic continuum: Ordination space position estimated from imaging spectroscopy. Journal of Vegetation Science 18: 131-140.

Schuster, C., Schmidt, T., Conrad, C., Kleinschmit, B., \& Förster, M. 2015. Grassland habitat mapping by intra-annual time series analysis - Comparison of RapidEye and TerraSAR-X satellite data. International Journal of Applied Earth Observation and Geoinformation 34: 25-34.

Shoko, C., \& Mutanga, O. 2017. Seasonal discrimination of C3 and C4 grasses functional types: An evaluation of the prospects of varying spectral configurations of new generation sensors. International Journal of Applied Earth Observation and Geoinformation 62: 47-55.

Stenzel, S., Feilhauer, H., Mack, B., Metz, A., \& Schmidtlein, S. 2014. Remote sensing of scattered Natura 2000 habitats using a one-class classifier. International Journal of Applied Earth Observation and Geoinformation 33: 211-217.

Stratford, C., Brewin, P., Acreman, M., \& Mountford, O. 2015. A simple model to quantify the potential trade-off between water level management for ecological benefit and flood risk. Ecohydrology \& Hydrobiology 15: 150-159.

Thomas, V., Treitz, P., Jelinski, D., Miller, J., Lafleur, P., \& McCaughey, J.H. 2003. Image classification of a northern peatland complex using spectral and plant community data. Remote Sensing of Environment 84: 83-99.

Tichý, L., Chytrý, M., \& Botta-Dukát, Z. 2014. Semi-supervised classification of vegetation: preserving the good old units and searching for new ones. Journal of Vegetation Science 25: 1504-1512.

Vanden Borre, J., Paelinckx, D., Mücher, C.A., Kooistra, L., Haest, B., De Blust, G., \& Schmidt, A.M. 2011. Integrating remote sensing in Natura 2000 habitat monitoring: Prospects on the way forward. Journal for Nature Conservation 19: 116-125.

Violle, C., Bonis, A., Plantegenest, M., Cudennec, C., Damgaard, C., Marion, B., Le Cœur, D., \& Bouzillé, J.-B. 2011. Plant functional traits capture species richness variations along a flooding gradient. Oikos 120: 389-398.

Wiser, S.K., \& Cáceres, M. 2013. Updating vegetation classifications: an example with New Zealand's woody vegetation. Journal of Vegetation Science 24: 80-93. 
Zlinszky, A., Deák, B., Kania, A., Schroiff, A., \& Pfeifer, N. 2015. Mapping Natura 2000 Habitat Conservation Status in a Pannonic Salt Steppe with Airborne Laser Scanning. Remote Sensing 7: 2991-3019.

Zlinszky, A., \& Kania, A. 2016. Will it blend? Visualization and accuracy evaluation of highresolution fuzzy vegetation maps. International Archives of the Photogrammetry, Remote Sensing \& Spatial Information Sciences 41:

Zlinszky, A., Schroiff, A., Kania, A., Deák, B., Mücke, W., Vári, Á., Székely, B., \& Pfeifer, N. 2014. Categorizing Grassland Vegetation with Full-Waveform Airborne Laser Scanning: A Feasibility Study for Detecting Natura 2000 Habitat Types. Remote Sensing 6: 8056-8087. 


\section{Supporting information}

Appendix S1. Fuzzy accuracy assessment

Appendix S2. Dendrogram and silhouette plots

Appendix S3. Full synoptic table

Appendix S4. Reference and classified membership matrix

Appendix S5. Full map of the plant communities

Appendix S6. Importance of spectral bands on classification accuracy 